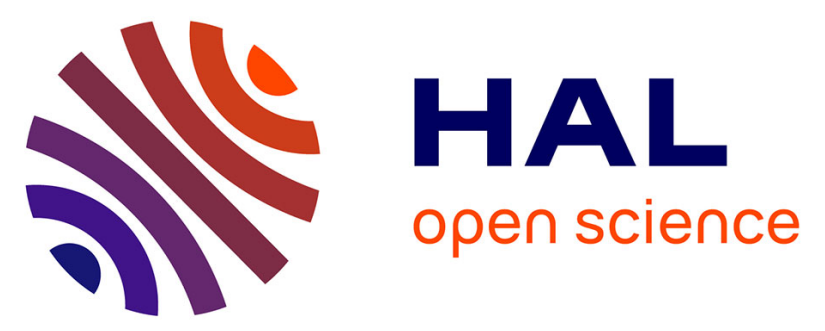

\title{
Use of mouse model in pharmacokinetic studies of poorly water soluble drugs: Application to fenofibrate
}

Badr Bahloul, Fathi Safta, Mohamed Ali Lassoued, Hélène Dhotel, Johanne

Seguin, Nathalie Mignet, Souad Sfar

\section{- To cite this version:}

Badr Bahloul, Fathi Safta, Mohamed Ali Lassoued, Hélène Dhotel, Johanne Seguin, et al.. Use of mouse model in pharmacokinetic studies of poorly water soluble drugs: Application to fenofibrate. Journal of Drug Delivery Science and Technology, 2018, 43, pp.149 - 153. 10.1016/j.jddst.2017.10.006 . hal-03078844

\section{HAL Id: hal-03078844 \\ https://hal.science/hal-03078844}

Submitted on 27 Dec 2020

HAL is a multi-disciplinary open access archive for the deposit and dissemination of scientific research documents, whether they are published or not. The documents may come from teaching and research institutions in France or abroad, or from public or private research centers.
L'archive ouverte pluridisciplinaire HAL, est destinée au dépôt et à la diffusion de documents scientifiques de niveau recherche, publiés ou non, émanant des établissements d'enseignement et de recherche français ou étrangers, des laboratoires publics ou privés. 


\section{Accepted Manuscript}

Use of mouse model in pharmacokinetics study of poorly water soluble drugs:

Application to fenofibrate

Badr Bahloul, Fathi Safta, Mohamed Ali Lassoued, Hélène Dhotel, Johanne Seguin,

Nathalie Mignet, Souad Sfar

ap AP

PII:

S1773-2247(17)30369-6

DOI:

10.1016/j.jddst.2017.10.006

Reference: JDDST 488

To appear in: Journal of Drug Delivery Science and Technology

Received Date: 11 May 2017

Revised Date: 4 October 2017

Accepted Date: 8 October 2017

Please cite this article as: B. Bahloul, F. Safta, M.A. Lassoued, Héè. Dhotel, J. Seguin, N. Mignet, S. Sfar, Use of mouse model in pharmacokinetics study of poorly water soluble drugs: Application to fenofibrate, Journal of Drug Delivery Science and Technology (2017), doi: 10.1016/j.jddst.2017.10.006.

This is a PDF file of an unedited manuscript that has been accepted for publication. As a service to our customers we are providing this early version of the manuscript. The manuscript will undergo copyediting, typesetting, and review of the resulting proof before it is published in its final form. Please note that during the production process errors may be discovered which could affect the content, and all legal disclaimers that apply to the journal pertain. 

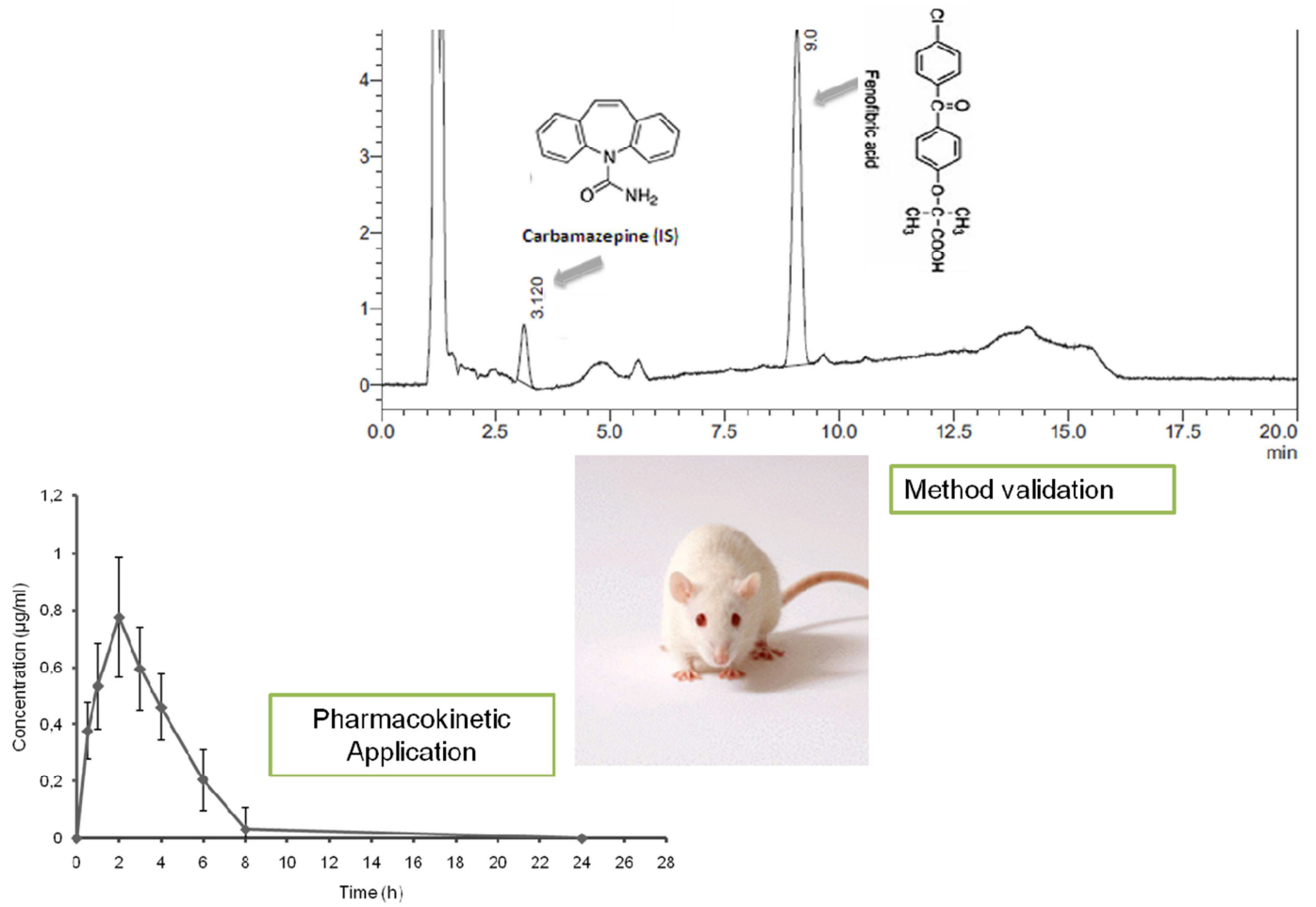

Method validation 
1

\section{Use of mouse model in pharmacokinetics study of poorly}

\section{water soluble drugs: Application to fenofibrate}

\section{Author names and affiliation}

Badr Bahloul ${ }^{\text {a, }}$, Fathi Safta ${ }^{\text {a }}$, Mohamed Ali Lassoued ${ }^{\text {a }}$, Hélène Dhotel $^{\mathrm{b}}$, Johanne Seguin ${ }^{\mathrm{b}}$, Nathalie Mignet ${ }^{\mathrm{b}}$, Souad Sfar ${ }^{\mathrm{a}}$.

${ }^{a}$ Laboratory of Pharmaceutical, Chemical and Pharmacological Drug Development LR12ES09, Faculty of Pharmacy, University of Monastir, Tunisia

${ }^{b}$ CNRS UMR 8258 - Inserm U1022, Paris Descartes University, Sorbonne Paris Cité, Paris, F-75006, France.

* Corresponding author

Badr Bahloul

Tel. $+21698418241 \quad$ Fax: +21673461830

E-mail : Badrpharm07@gmail.com

Permanent Address: Faculty of Pharmacy, Laboratory of Pharmaceutical, Chemical and Pharmacological Drug Development LR12ES09. 01 rue Avicenne, 5000 Monastir, Tunisia 
ABSTRACT
19

20

Fenofibrate has recently been used as drug model in several studies with the objective of optimizing the development of some drug delivery systems to overcome the problem of poor aqueous solubility of the newly discovered API. The adequacy of the drug delivery systems to improve the oral bioavailability of encapsulated drug is generally evaluated by a pharmacokinetic study. The use of mouse as animal model for pharmacokinetic studies has become more important in the last decade because of many similarities with the human model in terms of the mechanisms of absorption, metabolism and elimination. Nevertheless, the mouse is often hampered by the very small volumes of blood that could be obtained during sampling. The aim of this work was to overcome the problem of lower volumes of plasma withdrawn by developing an appropriate protocol for sample preparation and a suitable HPLC method for drug quantification in mouse plasma. Linear calibration curve was obtained over the concentration range from $0,16 \mu \mathrm{g} / \mathrm{mL}$ to $32 \mu \mathrm{g} / \mathrm{mL}\left(r^{2}=0,9999\right)$ with LLOQ of $0,16 \mu \mathrm{g} / \mathrm{mL}$ The RSD in both intra-run and inter-run precision study was less than $11 \%$ and the extraction recoveries were above $91.9 \%$. The reproducible method was successfully applied to the pharmacokinetic study of fénofibrate in mouse.

KEY WORDS: Fenofibric acid, HPLC-UV, Pharmacokinetic, mouse, fenofibrate, poorly water soluble drugs 


\section{INTRODUCTION}

Fenofibrate, is a well-studied lipid regulating agent used for the treatment of hypercholesterolemia and hyper-triglyceridemia. After absorption, the drug is completely hydrolyzed by esterases in its active metabolite, the fenofibric acid, [1] which is eliminated with a half-life of 20 hours in human after one daily dosage. Its maximal plasma concentration is obtained around 3 to 4 hours post dosage.

Fenofibrate is practically insoluble in water and exhibits an extremely poor oral bioavailability [2]. Therefore, fenofibrate has recently been used as drug model in several studies with the objective of optimizing the development of some drug delivery systems to overcome the problem of poor aqueous solubility characterizing more than $50 \%$ of the newly discovered API. Among these systems : solid lipid nanoparticles [3] nanocrystals [4], nanosuspension [5], selfmicroemulsufying systems [6] that were developed using fenofibrate as a drug model. The adequacy of these drug delivery systems to improve the oral bioavailability of encapsulated drug is generally evaluated by a pharmacokinetic study which requires a suitable animal species that should closely resembles to human in terms of the mechanisms of absorption and elimination of the active ingredient.

The rat appears to be the primary species most commonly used in preclinical pharmacokinetic studies. However, it was shown that the oral bioavailability values and the metabolic enzymatic levels in intestine are distinct between humans and rats [7].

Moreover, the use of the mouse as an animal model for pharmacokinetic studies has become more important in predicting oral bioavailability due to several similarities in the absorption, metabolism and elimination processes between humans and mice [8]. Besides, the presence of gall bladder in mice led to the occurrence of an absorption mechanism, entitled collisional transfer, by which highly lipophilic drugs are diffused through the glycocalyx when they are intercalated in the bile acids (fasting state) or in the mixed micelles of bile acids (fasted state) [9]. As rats do not possess a gall bladder, we chose to perform our study in mice. Nevertheless, the mouse exhibits a particular challenge because of the very small volumes of blood that could be obtained during sampling and hence impediments for pharmacokinetics $[\mathbf{8}, \mathbf{1 0}]$.

The aim of this work was at first to overcome the problem of lower volumes of plasma withdrawn by developing a one-step processing method for samples preparation that would be rapid in applying and ensuring at least $90 \%$ of drug extraction efficiency. Secondly, a fast and 
sensitive analytical method was developed for the dosage of the active metabolite of fenofibrate (fenofibric acid) by HPLC-UV.

This quantification method was subsequently validated according to the recommendations of the SFSTP [11] and the FDA guideline for validation of bioanalytical methods[12]. The feasibility of the animal model and the extraction protocol were evaluated by carrying out a pharmacokinetic application to fenofibrate in its commercialized form LIPANTHYL® with an oral dose corresponding to $5 \mathrm{mg} / \mathrm{kg}$.

\section{MATERIALS AND METHODS}

\subsection{Chemicals and reagents}

Fenofibric acid (purity $\geq 98.0 \%$ ) was provided from Sigma-Aldrich and the internal standard (I.S.), carbamazepine ( $\geq 99.0 \%$ purity) was purchased from Sigma-Aldrich (China). Methanol and deionized water of HPLC grade were bought from Carlo Erba (France). Ammonium acetate was of analytical grade was purchased from Sigma-Aldrich (Netherlands) Hydrochloric acid and diethyl ether were acquired from Carlo Erba (France).. Normal mouse plasma was brought from Sigma-Aldrich (USA) and stored at $-20^{\circ} \mathrm{C}$.

\subsection{Chromatographic conditions}

Analyses were performed on a Shimadzu HPLC Class VP series (Shimadzu, Kyoto, Japan) which was composed of a LC-10ADvp quadratic pump, an auto-sampler (model SIL10Avp Shimadzu), a variable UV-Visible wavelength detector (model SPD 10Avp; Shimadzu) and the data were analyzed by Class-VP series software, version 5.03 (Shimadzu, Japan). The analytical column used was LiChrospher $100 \mathrm{RP} 8(125 \mathrm{~mm} \times 4.6 \mathrm{~mm}$ I.D, $5 \mu \mathrm{m}$ particle size). The detection wavelength was fixed at $287 \mathrm{~nm}$ and the column oven temperature was set at $35^{\circ}$ C.Elution was obtained by applying the gradient steps summarized in table 1 and corresponding to solvents A (Methanol) and B ((5 mM ammonium acetate buffer ( $\mathrm{pH} 3.3))$. In all cases the flow rate was $1.5 \mathrm{ml} / \mathrm{mn}$ and the UV detection was achieved at a wavelength of 287 nm. 
Table 1. Gradient elution system for separation of fenofibric acid and internal standard

\begin{tabular}{lcc}
\hline & \multicolumn{2}{c}{ Gradient } \\
\cline { 2 - 3 } $\begin{array}{l}\text { Cumulative time of } \\
\text { acquisition (min) }\end{array}$ & $\begin{array}{c}\text { \% Solvent A } \\
\text { Methanol }\end{array}$ & $\begin{array}{c}\text { \% Solvent B } \\
\text { mM ammonium acetate buffer } \\
(\mathrm{pH} \mathrm{3.3)})\end{array}$ \\
\hline 5 & 56 & 44 \\
10.5 & 66 & 34 \\
12.5 & 76 & 24 \\
13 & 66 & 34 \\
\hline
\end{tabular}

\subsection{Preparation of standard and stock solutions:}

The Stock solution of fenofibric acid was prepared in methanol at a concentration of $1600 \mu \mathrm{g} / \mathrm{ml}$.

In the other hand, the preparation of the internal standard stock solution was done at a concentration of $4.7 \mu \mathrm{g} / \mathrm{ml}$ by dissolving $2.35 \mathrm{mg}$ carbamazepine in $500 \mathrm{ml} \mathrm{HCl} \mathrm{(1M).}$

Then, the standard solutions of fenofibric acid with concentrations of 1600, 800, 500, 160, 80, 16 and $8 \mu \mathrm{g} / \mathrm{ml}$ were prepared after serial volumetric dilution of fenofibric acid stock solution in methanol.

These solutions were prepared and stored in appropriate conditions (at $-20^{\circ} \mathrm{C}$ ) until analysis.

\subsection{Extraction methods and sample preparation procedure:}

$25 \mu \mathrm{L}$ aliquot of mouse plasma was mixed with $12.5 \mu \mathrm{L}$ of the internal standard solution in $1.5 \mathrm{ml}$ Eppendorff tube.

Precipitation of the plasma proteins has been carried out by adding $250 \mu \mathrm{L}$ of methanol then by vortexing the mixture for 30 minutes using a vortex mixer (Eppendorf, Hamburg, Germany).. Afterward the samples were placed in an ice bath for $60 \mathrm{~min}$, followed by centrifugation for 10 minutes at $12.000 \mathrm{rpm}\left(4^{\circ} \mathrm{C}\right)$. The top layer was injected $(20 \mu \mathrm{L})$ into the HPLC system for analysis. 


\subsection{Calibration curves and quality control plasma samples preparation}

Calibration curves of fenofibric acid were prepared with concentration levels of 32 , $16,3.2,1.6,0.32$ and $0.16 \mu \mathrm{g} / \mathrm{ml}$ by spiking $0.5 \mu \mathrm{L}$ of the standard solution in $24.5 \mu \mathrm{L}$ of mouse plasma. This ratio of 2:100 was chosen in order to avoid plasma alteration with the standard solution [13].

Three control samples (QC) were prepared in blank mouse plasma at different concentrations of fenofibric acid $\left(0.64,16\right.$ and 25.6) $\mu \mathrm{g} / \mathrm{ml}$. All samples were conserved at $-80{ }^{\circ} \mathrm{C}$ until analysis.

A single set of quality controls and standards were analyzed each day of the overall work using the same procedure described above for plasma samples.

\subsection{Method validation:}

A complete validation of the used method for the determination of fenofibric acid in mouse plasma was done according to the FDA guideline for validation of bioanalytical methods [12] and to the SFSTP recommendations [11].

The method has been validated for selectivity, linearity, lower limit of quantification (LLOQ), precision and accuracy, stability and recovery.

\subsubsection{Selectivity}

Chromatograms of drug-free mouse plasma were compared $(n=6)$. All samples were processed using the protein precipitation procedure in order to ensure the absence of endogenous peaks co-eluted with fenofibric acid or the internal standard.

\subsubsection{Precision and accuracy}

To assess the intra- and inter-day accuracy and precision, repetitive measurements of the three QC sample concentrations $(0.64,16$ and $25.6 \mu \mathrm{g} / \mathrm{ml})$ were realized. Intra-day accuracy was assessed through the QC samples analyzed in replicates of five per day. The inter-day precision was determined by performing the same procedure once a day during three consecutive days. Precision and accuracy were expressed as relative standard deviation (RSD) and relative error (RE) respectively. The precision and accuracy acceptance criterion for each QC sample concentration was within $\pm 15 \%$.

\subsubsection{Linearity and limit of quantification}


To assess the linearity, six-point standard curves had been run within the concentration range $0.16-32 \mu \mathrm{g} / \mathrm{ml}$ on three different days with replicates of four for each concentration per day $(n=4)$.

Standard curves were fitted by plotting peak area ratio of fenofibric acid to internal standard versus the corresponding concentration. Calibration curves were obtained by least-squares linear regression method using weight scheme as $\mathrm{x}(\mathrm{x}=$ concentration $)$

The acceptance criterion of the coefficient of correlation for the calibration curves was 0.999 or greater and every back-determined standard concentration had to be within $15 \%$ deviation with the exception of the lower limit of quantification (LLOQ) that was within $20 \%$. The LLOQ is corresponding to the lowest concentration on the standard curve which could be evaluated with adequate precision and accuracy.

\subsubsection{Recovery}

Extraction recovery was calculated by analyzing the three QC samples (three samples each) in order to evaluate the extraction performance of the used method.

The recoveries had been evaluated by comparing the peak areas of the extracted samples with those in which the analytes were subsequently added.

\subsubsection{Stability study}

Stability of fenofibric acid in mouse plasma during processing and storage was checked using the QC samples at three distinct concentrations that were analyzed under different conditions.

QC samples were analyzed after short-term storing at room temperature for $24 \mathrm{~h}$, after longterm storage : one month at $-20^{\circ} \mathrm{C}$, and after three freeze-thaw stability cycles. The postprocessing stability was also evaluated by analyzing reconstituted QC samples that were kept in auto-sampler for $24 \mathrm{~h}$.

Every stability study was carried out in replicates of four for each QC sample..

\subsection{Application to pharmacokinetic study}

The in vivo study was carried out according to the EU Directive 2010/63/EU related to animal experiments. 8-week-old male BALB/cJRj mice (Janvier, St. Genest de Lisle, 
179 France), weighing approximately 20-22 g were housed in a controlled environment and were

180

181

182

183

184

185

186

187

188

189

190

191

192

193

194

195

196

197

198

199

200

201

202

203

204

205

206 fasted overnight for 12 hours, nevertheless they were allowed to have free access to water.

The animals were dosed via oral gavage with $5 \mathrm{mg} / \mathrm{kg}$ of fenofibrate. The compound was orally administrated as suspensions of LIPANTHYL micronized.

Blood samples were collected at $0 \mathrm{~h}$ (pre-dose) $0.5,1,2,3,4,6,8$, and $24 \mathrm{~h}$ post-dose from the tail vein using a sparse sampling schedule consisting of two blood samples for each mouse and 6 mice per time point. The samples were transferred to heparinized tube and centrifuged at $10,000 \mathrm{rpm}$ for $10 \mathrm{~min}$. The resulting plasma was separated and kept frozen at $-80^{\circ} \mathrm{C}$ prior analysis.

\section{RESULTS AND DISCUSSION}

\subsection{Method development}

The separation of fenofibric acid and carbamazepine (internal standard) from the biological endogenous components in mouse plasma was found to be efficient and remarkably within satisfactory range. Various combinations of mobile phase, isocratic and gradient systems were investigated to achieve the optimum separation condition. We found that the best wavelength for detection was $287 \mathrm{~nm}$. The used mobile phase was Methanol and ammonium acetate buffer $(5 \mathrm{mM},(\mathrm{pH} 3.3)$. And optimal elution was attained by applying the gradients steps (summarized in table 1) of solvent A (Methanol) and solvent B (ammonium acetate buffer $(5 \mathrm{mM},(\mathrm{pH} 3.3))$ at a flow rate of $1.5 \mathrm{ml} / \mathrm{min}$. The retention times of $\mathrm{I} . \mathrm{S}$ and fenofibric acid were $3 \mathrm{~min}$ and 9 min respectively.

Clear supernatants, which were immediately injected into HPLC, were obtained after centrifugation of plasma samples that had been simply treated with Methanol and then cooled to $0{ }^{\circ} \mathrm{C}$ by immersion in an ice bath for 30 minutes. The sample processing is consequently convenient, inexpensive, and rapid. Furthermore, no evaporation step or a reconstitution phase was needed. Otherwise during the method development, protein precipitation step was also evaluated using diethyl ether but recovery, extraction rate and selectivity were found to be unsatisfactory specially compared to the method using methanol which allowed a high recovery and selectivity. 


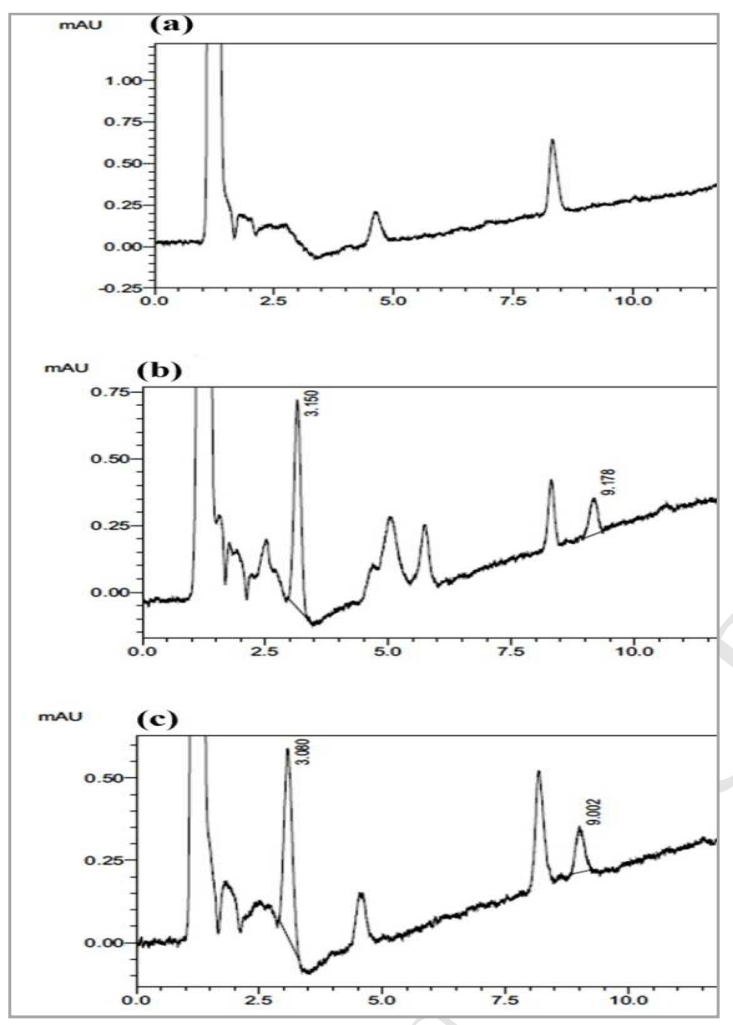

Fig. 1. HPLC chromatogram of (a) blank mouse plasma. (b) plasma sample spiked with standards of carbamazepine (Rt-3 min) and fenofibric acid at a concentration of $0.64 \mu \mathrm{g} / \mathrm{ml} \quad$ (Rt-9 $\min )$. plasma sample from a mouse, post dosing at $3 \mathrm{~h}$.

\subsection{Selectivity study}

Six different sources of blank plasma were screened in order to investigate any eventual interference from endogenous substances. Fig. 1 shows chromatograms obtained from the analysis of the extracted drug-free plasma, plasma sample spiked with fenofibric acid and the internal standard, and a plasma sample obtained from a mouse post dosing at $3 \mathrm{~h}$. The retention time for carbamazepine (internal standard) and fenofibric were, respectively, 3min and 9 min. With no endogenous compounds in the plasma eluted at the retention time of fenofibric acid and internal standard.

\subsection{Linearity and lower limit of quantification}

The peak areas ratio (Y) of fenofibric acid versus the internal standard (I.S) were proportional to the concentration of fenofibric acid ( $\mathrm{x}$ ) in plasma within the tested range $(0.16-32 \mu \mathrm{g} / \mathrm{ml})$. Blank mouse plasma spiked with the corresponding standard solutions giving concentrations of $0.16,0.32,1.6,3.2,16$ and $32 \mu \mathrm{g} / \mathrm{ml}$ were analyzed. Excellent linear correlation was 
224 obtained for all analytes over the entirestudied concentration range. The standard equation was $y=0,4316 x-0,0227$ and the correlation coefficient was $r^{2}=0.9999$. The analyte response at the lower limit of quantification (LLOQ) was found to be 5 times the response of the blank response $(\mathrm{S} / \mathrm{N}$ ratio greater than 5$)$ and was equal to $0.16 \mu \mathrm{g} / \mathrm{ml}$ for fenofibric acid. The accuracy and precision at the LLOQ were acceptable, with $8.5 \%$ RE and $2.06 \%$ RSD ( $n=5)$.

\subsection{Precision and accuracy}

230

231

232

233

234

The intra- and inter- day precision and accuracy results are summarized in Table 2. The RSD and RE were less than $11 \%$ for the intra- and inter-run precision and accuracy assays. These described results inferred that the developed method was precise and accurate.

Table 2. Intra- and inter-day precision and accuracy for the determination of fenofibric acid in mouse plasma.

\begin{tabular}{|c|c|c|c|c|c|c|}
\hline \multirow{3}{*}{$\begin{array}{l}\text { Spiked } \\
(\mu \mathrm{g} / \mathrm{ml})\end{array}$} & \multicolumn{3}{|c|}{ Intra-day precision and accuracy $(\mathrm{n}=5)$} & \multicolumn{3}{|c|}{ Inter-day precision and accuracy $(n=15)$} \\
\hline & & & RE & & & $\mathrm{RE}$ \\
\hline & measured (mean $\pm \mathrm{SD}) \mu \mathrm{g} / \mathrm{ml}$ & $\operatorname{RSD}(\%)$ & $(\%)$ & measured (mean $\pm \mathrm{SD}) \mu \mathrm{g} / \mathrm{ml}$ & $\operatorname{RSD}(\%)$ & (\%) \\
\hline 0.64 & $0.57 \pm 0.03$ & 4.82 & 10.00 & $0.58 \pm 0.04$ & 6.23 & 8.23 \\
\hline 16 & $15.02 \pm 1.02$ & 6.82 & 5.70 & $16.13 \pm 1.31$ & 8.09 & 1.22 \\
\hline 25.6 & $24.6 \pm 2.69$ & 10.92 & 3.51 & $25.75 \pm 1.73$ & 6.71 & -0.99 \\
\hline
\end{tabular}

\subsection{Recovery:}

236

237

The extraction recovery was calculated for the three quality control concentration levels of fenofibric acid with three replicates for each level. The recovery of fenofibric acid at concentrations of $0.64,16$ and $25.6 \mu \mathrm{g} / \mathrm{ml}$ were $93.39 \% \pm 1.06,91.98 \% \pm 6.83,92.49 \% \pm 8.25$, respectively. The recovery of carbamazepine at the working concentration was $98,10 \pm 3,348 \%$.

\subsection{Stability:}

The results of stability study, summarized in Table 3, showed that no significant degradation occurred to fenofibric acid during storage and extraction processes in mouse plasma samples. 
243 Table 3. Stability data of fenofibric acid in mouse plasma under different storage conditions $244 \quad(n=4)$

\begin{tabular}{|c|c|c|c|c|}
\hline storage conditions & $\begin{array}{l}\text { Added } \\
\text { concentration } \\
\mu \mathrm{g} / \mathrm{ml}\end{array}$ & $\begin{array}{l}\text { Found } \\
\text { concentration } \\
\mu \mathrm{g} / \mathrm{ml}\end{array}$ & $\begin{array}{l}\text { Relative } \\
\text { Error } \\
(\%)\end{array}$ & $\begin{array}{l}\mathrm{RSD} \\
(\%)\end{array}$ \\
\hline & 0.64 & 0.710 & -11.313 & 7.905 \\
\hline \multirow[t]{3}{*}{ Short-term stability $(24 \mathrm{~h}$, room temperature, $\mathrm{n}=4$ ) } & 16 & 15.645 & 1.833 & 1.464 \\
\hline & 25.6 & 27.561 & -8.084 & 6.027 \\
\hline & 0.64 & 0.652 & -2.296 & 4.780 \\
\hline \multirow[t]{3}{*}{ Post-preparative stability $(24 \mathrm{~h}$, room temperature, $\mathrm{n}=4)$} & 16 & 16.177 & -1.503 & 5.757 \\
\hline & 25.6 & 26.223 & -2.833 & 2.466 \\
\hline & 0.64 & 0.689 & -8.054 & 5.672 \\
\hline \multirow[t]{2}{*}{ Long-term stability $(30 \mathrm{~d},-20 \circ \mathrm{C}, \mathrm{n}=4)$} & 16 & 15.608 & 2.070 & 1.782 \\
\hline & 25.6 & 26.079 & -2.271 & 2.313 \\
\hline \multirow{3}{*}{$\begin{array}{l}\text { Freeze and thaw stability (three cycles, }-20 \circ \mathrm{C} / \text { room } \\
\text { temperature, } n=4 \text { ) }\end{array}$} & 0.64 & 0.693 & -8.769 & 6.803 \\
\hline & 16 & 16.088 & -0.942 & 7.392 \\
\hline & 25.6 & 26.884 & -5.426 & 4.421 \\
\hline
\end{tabular}

245 3.7. Application to pharmacokinetic study:

246 After validation, the proposed method was applied for the determination of the fenofibric acid

247 concentration in mouse plasma after oral administration of $5 \mathrm{mg} / \mathrm{kg}$ fenofibrate to 24 male

$248 \mathrm{BALB} / \mathrm{cJRj}$ mice. Fig 2. Illustrates the mean plasma concentration/time curve of fenofibric 249 acid. The plasma level of fenofibric acid reached a maximum concentration level (Cmax) 250 equal to $0.831 \pm 0.119 \mu \mathrm{g} / \mathrm{ml}$, in $(\mathrm{Tmax})$ equal to $2 \mathrm{~h}$ and the $\mathrm{AUC}_{0-24 \mathrm{~h}}$ was $4.240 \pm$ $2510.571 \mu \mathrm{g} . \mathrm{h} / \mathrm{ml}$. The obtained pharmacokinetic profiles were in close agreement with the PK 252 profiles of fenofibric acid which were reported recently in literature [14-16]. 


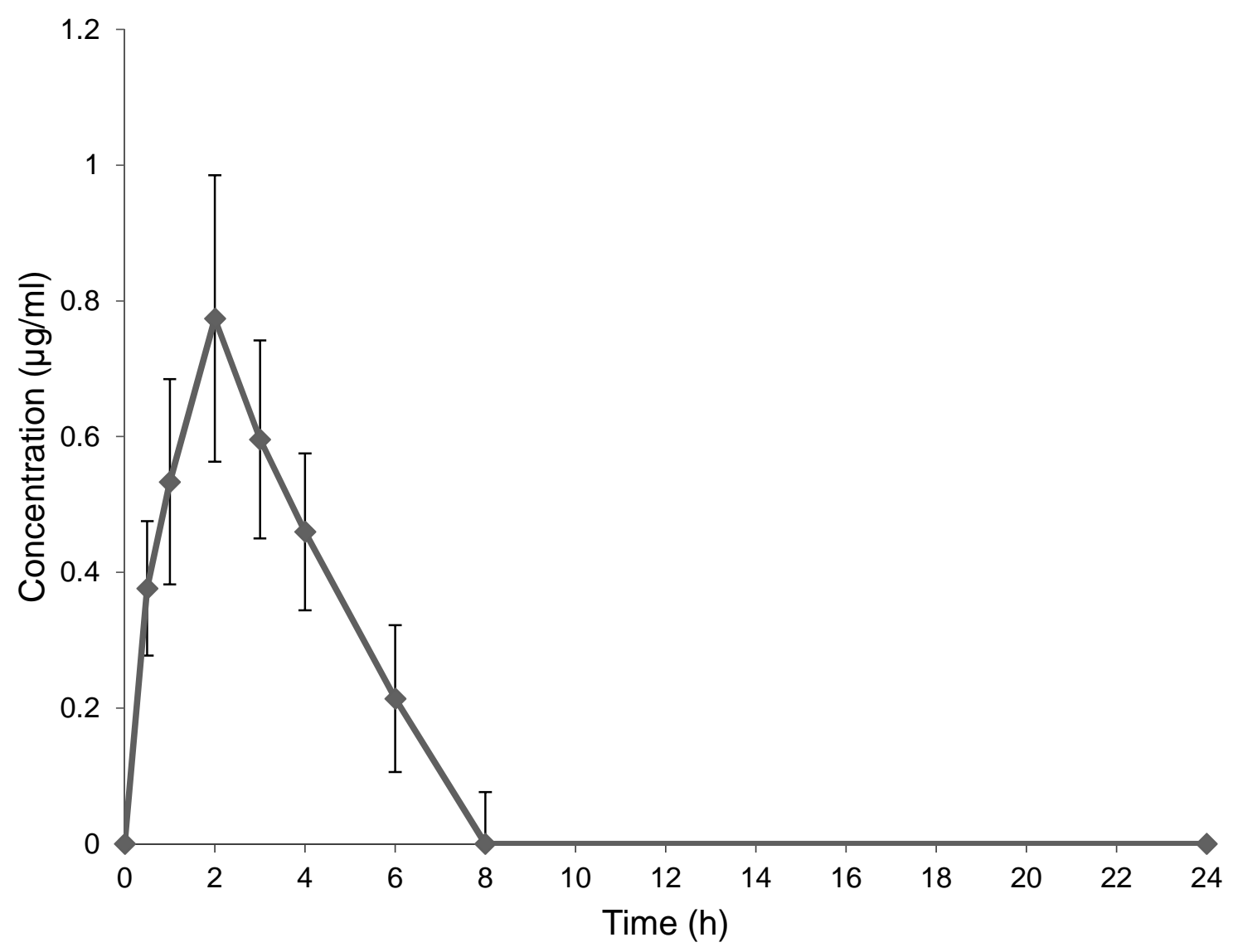

Fig 2. Mean plasma concentration-time profiles of fenofibric acid in plasma following a single oral dose of $5 \mathrm{mg} / \mathrm{kg}$ fenofibrate to 24 male BALB/cJRj mice.

\section{CONCLUSION}

A HPLC method for the determination of fenofibric acid in mouse plasma has been developed and completely validated for the first time. The preparation procedure of plasma samples was suitable without any need to a reconstitution process or an extraction-evaporation phase. The method was reproducible and the extraction recoveries were above $91.9 \%$. Linear calibration curve was obtained over the concentration range from $0,16 \mu \mathrm{g} / \mathrm{mL}$ to $32 \mu \mathrm{g} / \mathrm{mL}\left(\mathrm{r}^{2}=0,9999\right)$ with LLOQ of $0,16 \mu \mathrm{g} / \mathrm{mL}$ The RSD in both intra-run and inter-run precision study was less than $11 \%$. Besides, this study has shown that it was possible to overcome the problem of lower volumes of plasma withdrawn by the developed sample preparation process and the drug quantification method. Hence, the feasibility of mouse model to be used in pharmacokinetics study of fenofibrate was confirmed as well as the extraction protocol with reference to the results of analytical validation and successful application of the pharmacokinetic study. Finally, this method may allow scientists to perform rapid and robust oral bioavailability studies of 
fenofibrate in mice when it is used as drug model in some new drug delivery systems and innovative formulations strategies.

\section{REFERENCES}

[1] G. Wang, J. Guo, F. Meng, X. Song, B. Zhong, Y. Zhao, Development of a sensitive liquid chromatography/tandem mass spectrometry method for the determination of fenofibric acid in rat plasma, Biomedical Chromatography, 26 (2012) 497-501.

[2] B. Bahloul, M.A. Lassoued, S. Sfar, A novel approach for the development and optimization of self emulsifying drug delivery system using HLB and response surface methodology: application to fenofibrate encapsulation, International journal of pharmaceutics, 466 (2014) 341-348.

[3] C.M. Patel, M. Chakraborty, Z. Murthy, Preparation of fenofibrate nanoparticles by combined stirred media milling and ultrasonication method, Ultrasonics sonochemistry, 21 (2014) 1100-1107.

[4] H. Zhang, Y. Meng, X. Wang, W. Dai, X. Wang, Q. Zhang, Pharmaceutical and pharmacokinetic characteristics of different types of fenofibrate nanocrystals prepared by different bottom-up approaches, Drug delivery, 21 (2014) 588-594.

[5] Y. Xu, Y. Wang, X.M. Li, Q. Huang, W. Chen, R. Liu, B. Chen, P. Wei, Study on the release of fenofibrate nanosuspension in vitro and its correlation with in situ intestinal and in vivo absorption kinetics in rats, Drug development and industrial pharmacy, 40 (2014) 972979.

[6] L. Xiumin, G. Man, L. Minzi, J. Yinghua, Q. Dongqin, The in vitro and in vivo Evaluation of Fenofibrate with a Self-Microemulsifying Formulation, Current drug delivery, 12 (2015) 308-313.

[7] X. Li, Oral bioavailability: basic principles, advanced concepts, and applications, John Wiley \& Sons, 2011.

[8] R. Mannhold, H. Kubinyi, G. Folkers, H. van de Waterbeemd, B. Testa, Drug bioavailability: estimation of solubility, permeability, absorption and bioavailability, John Wiley \& Sons, 2009.

[9] P. Gao, W. Morozowich, Development of supersaturatable self-emulsifying drug delivery system formulations for improving the oral absorption of poorly soluble drugs, Expert opinion on drug delivery, 3 (2006) 97-110. 
[10] A. Hem, A.J. Smith, P. Solberg, Saphenous vein puncture for blood sampling of the mouse, rat, hamster, gerbil, guineapig, ferret and mink, Laboratory animals, 32 (1998) 364-368.

[11] P. Hubert, J. Nguyen-Huu, B. Boulanger, E. Chapuzet, P. Chiap, N. Cohen, P. Compagnon, W. Dewé, M. Feinberg, M. Lallier, Validation des procédures analytiques quantitatives Harmonisation des démarches, STP Pharma Pratiques, 13 (2003) 101-138.

[12] Food, D. Administration, FDA guidance for industry: bioanalytical method validation. Rockville, MD: US Department of Health and Human Services, Food and Drug Administration, Center for Drug Evaluation and Research, 1 (2001) 124-129.

[13] O. Nicolas, C. Farenc, F. Bressolle, Stratégie de validation de méthodes de dosage en bioanalyse en vue d'études pharmacocinétiques et toxicologiques, in: Annales de Toxicologie Analytique, EDP Sciences, 2004, pp. 118-127.

[14] B. Bahloul, M.A. Lassoued, J. Seguin, R. Lai-Kuen, H. Dhotel, S. Sfar, N. Mignet, Selfemulsifying drug delivery system developed by the HLB-RSM approach: Characterization by transmission electron microscopy and pharmacokinetic study, International journal of pharmaceutics, 487 (2015) 56-63.

[15] Y. Chen, Y. Lu, J. Chen, J. Lai, J. Sun, F. Hu, W. Wu, Enhanced bioavailability of the poorly water-soluble drug fenofibrate by using liposomes containing a bile salt, International journal of pharmaceutics, 376 (2009) 153-160.

[16] T.T. Do, M. Van Speybroeck, R. Mols, P. Annaert, J. Martens, J. Van Humbeeck, J. Vermant, P. Augustijns, G. Van den Mooter, The conflict between in vitro release studies in human biorelevant media and the in vivo exposure in rats of the lipophilic compound fenofibrate, International journal of pharmaceutics, 414 (2011) 118-124. 